\title{
Blindness Incidence in Germany
}

\author{
A Population-Based Study from Württemberg-Hohenzollern
}

\author{
H.G. Krumpaszky ${ }^{a}$ R. Lüdtke ${ }^{a} \quad$ A. Mickler ${ }^{b} \quad$ V. Klauss ${ }^{c}$ H.K. Selbmann ${ }^{a}$ \\ alnstitute for Medical Information Processing, University of Tübingen, bSocial Services, Stuttgart, and \\ cUniversity Eye Clinic Munich, Germany
}

\section{Key Words}

Blindness incidence - Causes of blindness .

Epidemiology

\begin{abstract}
Few data on the incidence of blindness in Germany are available. We analysed causes of legal blindness for the region Württemberg-Hohenzollern (population 5.5 million) in order to help fill in this gap. Material and Methods: Population-based investigation on the incidence of legal blindness (visual acuity $<1 / 50$ ) based on materials from the social servies. Age-dependent blindness incidences were modelled via logistic regression models. Results: 647 blind persons were newly registered in 1994 (blindness incidence 11.6/100,000). The blindness incidence is moderate in infants $(4.5 / 100,000)$ and decreases further during childhood. At the age of 20 years, the incidence again rises to the former level and remains relatively constant. After the age of 60 years, the incidence increases sharply: 5-year odds ratios are $1.76(\mathrm{Cl}: 1.68-$ $1.85)$ in women and $1.72(\mathrm{Cl}: 1.60-1.84)$ in men. The blindness incidence is higher in women, 15.6/100,000, compared to $12.2 / 100,000$ in men. The major causes of blindness are: macular degeneration, 3.92/100,000; diabetic retinopathy, 2.01/100,000; glaucoma, 1.6/100,000; high myopia, 0.77/100,000; optic atrophy, 0.68/100,000; central nervous system-triggered blindness; 0.56/ 100,000 , and tapetoretinal degenerations, $0.52 / 100,000$. Discussion: Due to monetary incentives for the blind per-
\end{abstract}

\begin{tabular}{ll}
\hline KARGER & ( 1999 S. Karger AG, Basel \\
Fax +4161306 12 34 & 0030-3755/99/2133-0176\$17.50/0 \\
$\begin{array}{l}\text { E-Mail karger@karger.ch } \\
\text { www.karger.com }\end{array}$ & Accessible online at: \\
http://BioMedNet.com/karger
\end{tabular}

sons, social service files offer accurate and complete data. Besides macular degeneration, glaucoma and diabetic retinopathy are major causes of blindness. Thus, this study suggests further blindness prevention activities for diabetic retinopathy and glaucoma.

\section{Introduction}

Blindness causes human suffering and high social costs: over 1.2 billion DM blindness compensation payments are spent annually nation-wide in Germany for the 112,000 blind citizens [1]. Few data on the incidence of blindness in Germany are available. Such data are useful for estimating the needs for medical care, counselling, preventive and rehabilitative measures. Virtually all blind persons are registered with the social services. Thus, we analysed data from these institutions with regard to age-, sex-, and cause-specific blindness incidence in order to help in (long-term) planning for the prevention of blindness.

\section{Methods}

\section{Materials}

This study was planned as a population-based investigation on the incidence of blindness. It analysed materials from the social serivces of the region Württemberg-Hohenzollern, Germany. The social services cover a population of 5.5 million inhabitants. Files from all

H.G. Krumpaszky

Bachemer Strasse 4

D-50931 Köln (Germany)

Tel. +49 221446784, Fax +492214004378

E-Mail hans.krumpaszky@dgn.de 
Table 1. Coding of causes of blindness

\begin{tabular}{|c|c|c|}
\hline Cause of blindness & Included diagnostic categories & Excluded diagnostic categories \\
\hline Retinal detachment & Unspecified or traumatic & $\begin{array}{l}\text { Secondary cause (e.g. due to diabetic } \\
\text { retinopathy or high myopia) }\end{array}$ \\
\hline Catarct & Unspecified, congenital, traumatic & $\begin{array}{l}\text { Secondary cause (e.g. due to tapeto- } \\
\text { retinal degeneration) }\end{array}$ \\
\hline Chorioretinitis & Unspecified, choroideremia & \\
\hline Encephalomyelitis disseminata & Neuritis nervi optici & \\
\hline Glaucoma & $\begin{array}{l}\text { Unspecified, congenital, narrow-angle, } \\
\text { normal-tension glaucoma }\end{array}$ & $\begin{array}{l}\text { Secondary glaucoma (e.g. due to } \\
\text { trauma or diabetic retinopathy) }\end{array}$ \\
\hline Corneal opacification & Unspecified, traumatic & $\begin{array}{l}\text { Secondary (e.g. due to multiple } \\
\text { glaucoma operations) }\end{array}$ \\
\hline Iritis/uveitis & Unspecified & $\begin{array}{l}\text { Secondary (e.g. due to diabetic } \\
\text { retinopathy) }\end{array}$ \\
\hline Macular degeneration & Unspecified, Junius Kuhnt, juvenile & $\begin{array}{l}\text { Secondary (e.g. due to high myopia, } \\
\text { diabetic retinopathy) }\end{array}$ \\
\hline Malformations & Bulbs, papilla & Head and brain \\
\hline High myopia & $\begin{array}{l}\text { All sequelae of high myopia: retinal } \\
\text { detachment, fundal changes }\end{array}$ & \\
\hline Optic atrophy & $\begin{array}{l}\text { Leber's atrophy, Behr's atrophy, } \\
\text { traumatic, vascular }\end{array}$ & $\begin{array}{l}\text { Secondary (e.g. due to glaucoma, brain } \\
\text { injuries) }\end{array}$ \\
\hline Diabetic retinopathy & $\begin{array}{l}\text { All sequelae of diabetic eye disease: } \\
\text { detachment, proliferation, secondary } \\
\text { glaucoma, vitreous haemorrhage }\end{array}$ & \\
\hline Retinopathy of prematurity & Unspecified, retrolental fibroplasia & \\
\hline Tapetoretinal degeneration & All forms & \\
\hline $\begin{array}{l}\text { Central nervous-system- } \\
\text { triggered blindness }\end{array}$ & $\begin{array}{l}\text { Due to head tumours (also if surgically } \\
\text { removed), stroke, brain injuries, brain } \\
\text { hypoxia }\end{array}$ & \\
\hline Vascular occlusions of the eye & $\begin{array}{l}\text { Central artery occlusion, central } \\
\text { venous thrombosis, arteritis temporalis }\end{array}$ & \\
\hline Others & $\begin{array}{l}\text { Unspecified bulbus haemorrhage, } \\
\text { infections of the vitreous, unspecified } \\
\text { phthisis, eye tumours }\end{array}$ & \\
\hline
\end{tabular}

subjects that have been newly granted blindness compensation payments in Württemberg-Hohenzollern in 1994 have been included. According to the German legal definition of blindness, subjects applying for compensation payments must have a visual acuity of equal or less than $1 / 50$, or a visual impairment that is comparable to visual acuity $1 / 50$ (e.g. visual fields constricted to $5^{\circ}$ irrespective of visual acuity). For the latter cases, criteria of the German Ophthalmologic Society are applied [2].

Ophthalmologic expertises are required by the social services for granting social support. These were worked out by consultant ophthalmologists in private offices $(90.7 \%)$ or hospital departments $(9.3 \%)$. Data were recorded from copies of the original paper files. Complying with German data protection laws, the names, dates of birth and addresses of the blind subjects had previously been erased from the copies. Instead, sex, year of birth and home region of the blind individual were noted on the copy by the social services' staff.

Information on ocular status (findings, diagnosis, visual fields if visual acuity $>1 / 50$ ) and prognosis with regard to vision were extracted from the files.

\section{Definitions}

The cause of blindness was determined starting from the information given in the ophthalmologic expertises. If more than one disease was responsible for the visual loss, the cause of blindness was defined according to the following criteria:

- the disease that was responsible for the severer ocular pathology (e.g. macular degeneration if cataract and macular degeneration were given);

- the disease that impaired vision in the least seeing eye (e.g. glaucoma if amaurosis by trauma and glaucoma were given);

- the disease that had impaired vision more recently (e.g. vascular occlusion if glaucoma and central retinal artery occlusion were given).

Coding of Causes of Blindness

Causes of blindness were classified according to clinical terminology (table 1). This was done so because the materials that form the basis for this investigation used the clinical terminology. 


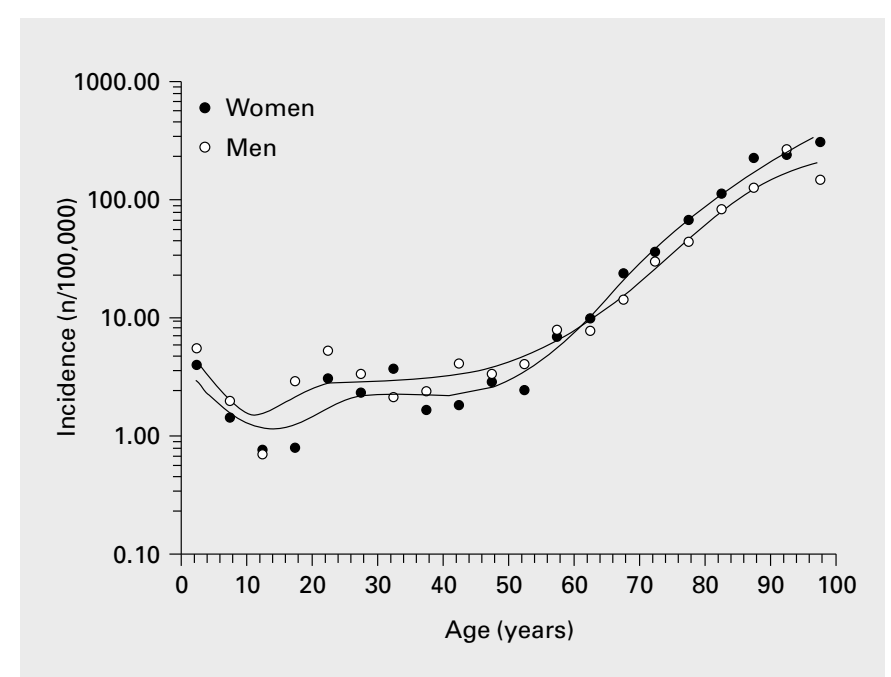

Fig. 1. Blindness incidence in Württemberg-Hohenzollern according to age and sex groups.

Table 2. Population-based blindness incidence (per 100,000) in Württemberg-Hohenzollern 1994

\begin{tabular}{|c|c|c|c|c|c|}
\hline \multirow{2}{*}{$\begin{array}{l}\text { Age } \\
\text { years }\end{array}$} & \multicolumn{2}{|l|}{ Blind } & \multicolumn{3}{|c|}{ Blindness incidence per 100,000} \\
\hline & male & female & male & female & population \\
\hline $1-4$ & 9 & 6 & 5.3 & 3.7 & 4.5 \\
\hline $5-9$ & 3 & 2 & 1.8 & 1.3 & 1.6 \\
\hline $10-14$ & 1 & 1 & 0.6 & 0.7 & 0.7 \\
\hline $15-19$ & 4 & 1 & 2.7 & 0.7 & 1.7 \\
\hline $20-24$ & 9 & 5 & 4.8 & 2.8 & 3.8 \\
\hline $25-29$ & 8 & 5 & 3.1 & 2.1 & 2.6 \\
\hline $30-34$ & 5 & 8 & 1.9 & 3.4 & 2.6 \\
\hline $35-39$ & 5 & 3 & 2.3 & 1.5 & 1.9 \\
\hline 40-44 & 7 & 3 & 3.7 & 1.6 & 2.7 \\
\hline $45-49$ & 5 & 4 & 3.0 & 2.5 & 2.8 \\
\hline $50-54$ & 7 & 4 & 3.7 & 2.2 & 2.9 \\
\hline $55-59$ & 14 & 12 & 7.3 & 6.4 & 6.8 \\
\hline $60-64$ & 10 & 13 & 7.2 & 9.2 & 8.2 \\
\hline $65-69$ & 15 & 31 & 13.4 & 22.6 & 18.5 \\
\hline 70-74 & 22 & 47 & 28.7 & 34.3 & 32.3 \\
\hline 75-79 & 16 & 50 & 42.2 & 65.0 & 57.4 \\
\hline 80-84 & 31 & 99 & 78.7 & 111.1 & 101.2 \\
\hline $85-89$ & 22 & 104 & 125.0 & 224.7 & 197.3 \\
\hline 90-94 & 12 & 34 & 262.2 & 237.9 & 243.8 \\
\hline$\geqslant 95$ & 1 & 9 & 144.9 & 315.2 & 282.1 \\
\hline Total & 206 & 441 & & & \\
\hline
\end{tabular}

Data Handling and Statistical Analysis

All data were recorded and processed in LARS, an information processing software system [3]. All statistical analyses were done with the statistical software package SAS [4].

Age-dependent blindness incidences were modelled via two separate sex-specific logistic regression models [5]. Each model fits a piecewise linear function, the change points were determined by the ages of 15,25 and 55 years, respectively. The results are presented by 5 -year odds ratios and their respective $95 \%$ confidence intervals (CI). Each odds ratio may be interpreted as the risk for blindness of a person with a determined age contrasted with the risk of the same persons with an age of 5 years less.

Indirect standardisation [6] was used to compare women and men (standardisation with respect to age distribution) and the study population with external populations (standardisation with respect to age and sex distribution where possible).

\section{Results}

At the fixing date (October 4, 1994), 5,356 blind persons were registered with the social serives in WürttembergHohenzollern. Given a population of 5.5 million, the blindness prevalence was $96 / 100,000$. The sex-specific prevalence was 76.7 in men and 115.4 per 100,000 in women.

In 1994, the number of the newly registered blind persons totalled 647 (table 2). This results in a blindness incidence of 11.6/100.000. On the basis of the total German population for 1994 [7], we estimate a blindness incidence of 11.3 (standardised for age and sex). This results in an estimated 9,451 newly blind persons each year for Germany. The blindness incidence is moderate in infants $(4.5 / 100,000)$ and decreases during childhood (fig. 1). Logistic regression reveals for this period a 5 -year odds ratio of 0.50 (CI: 0.24-1.02) in girls and 0.64 (CI: 0.38-1.07) in boys. In total, children under 10 years accounted for $3.1 \%$ of cases. At the age of 20 years, the incidence again rises to the former level. This rise entails 5 -year odds ratio of 1.78 (CI: $0.80-3.99)$ in women and 1.43 (CI: $0.80-2.57$ ) in men. Next, the incidence remains relatively constant for the next 30 years yielding 5-year odds ratios of 1.16 (CI: 1.04-1.30) in women and 1.05 (CI: 0.94-1.17) in men. After the age of 60 years, the incidence increases sharply. Here, the 5-year odds ratios are 1.76 (CI: 1.68-1.85) in women and 1.72 (CI: 1.60-1.84) in men. Consequently, one fifth of cases are subjects in the working age (15-65 years), but about half (48.2\%) of the newly blind persons are over 80 years of age. Moreover, nearly $10 \%$ of newly blind persons are 90 years and older.

Two out of $3(68.1 \%)$ newly blind subjects are women. After indirect standardisation for the women's age distribution [pers. commun., Statistical Office of Baden-Württemberg], it generally turns out that the blindness inci- 
dence is higher in women $(15.6 / 100,000)$ compared to men $(12.2 / 100,000)$. The incidence ratio between women and men is 1.28. However, before the age of 60 years, the blindness rate is higher in the male population yielding an incidence ratio of 0.74 . In contrast, after the age of 60 years, the female/male ratio switches to 1.43 .

\section{Residual Visual Acuity in Blind People}

Only a small minority $(6.3 \%)$ of blind persons have no residual vision (table 3 ). However, the majority $(70 \%)$ of blind subjects retain a visual acuity of 0.02 or less. In one fifth of the blind, the visual acuity ranges from 0.02 to 0.3 . In a small number of cases, the central vision exceeded 0.3 $(1.1 \%)$. These persons were considered blind due to extensive visual field loss.

\section{Causes of Blindness}

The distribution of causes of blindness in Württemberg-Hohenzollern is shown in table 4 . The three most frequent causes of blindness are: macular degeneration (incidence 3.92/100,000), diabetic retinopathy (incidence $2.01 / 100,000$ ) and glaucoma (incidence 1.6/100,000). Nearly two thirds of all newly blind individuals lost sight due to these three disease groups. High myopia $(0.77 /$ $100,000)$, optic atrophy $(0.68 / 100,000)$, central-nervoussystem-triggered blindness $(0.56 / 100,000)$ and tapetoretinal degenerations $(0.52 / 100,000)$ cause roughly one fifth of cases. A large spectrum of other diseases is responsible for the remaining small proportion of new cases of blindness: malformations, corneal opacification, cataract, vascular diseases of the eyes, retinal detachment and retinopathy of prematurity.

\section{Causes of Blindness According to Age Groups}

Only a small number of children (age $<15$ years) turned blind (incidence $2.3 / 100,000$ ). In this age category the most frequent cause is central-nervous-system-triggered blindness (table 5). Retinopathy of prematurity and optic atrophy still play a significant role.

In younger adults (age category 15-44 years) there is a wide spectrum of diseases leading to blindness. The most frequent cause is tapetoretinal degeneration (incidence $0.69 / 100,000$ ). Four diseases (central-nervous-systemtriggered blindness, malformations, diabetic retinopathy, optic atrophy) have a similar frequency (incidence 0.24$0.28 / 100,000$ of the population) in the newly blind population of $\mathrm{WH}$.

In older adults (age category 45-74 years), diabetic retinopathy is the leading cause of blindness affecting more than one third of cases $(3.74 / 100,000)$. Macular degenera-
Table 3. Residual visual acuity in blind subjects

\begin{tabular}{lrc}
\hline Visual acuity & Cases & Percentage \\
\hline Amaurosis & 41 & 6.3 \\
$<0.01$ & 123 & 19.0 \\
$0.01-0.02$ & 330 & 51.0 \\
$0.021-0.05$ & 91 & 14.1 \\
$0.051-0.3$ & 46 & 7.1 \\
$>0.3$ & 7 & 1.1 \\
$?$ & 9 & 1.3 \\
\hline Total & 647 & \\
\hline
\end{tabular}

Table 4. Causes of blindness in Württemberg-Hohenzollern

\begin{tabular}{lrl}
\hline Cause of blindness & Cases & $\begin{array}{l}\text { Incidence } \\
\text { per 100,000 }\end{array}$ \\
\hline Macular degeneration & 218 & 3.92 \\
Diabetic retinopathy & 112 & 2.01 \\
Glaucoma & 89 & 1.60 \\
High myopia & 43 & 0.77 \\
Optic atrophy & 38 & 0.68 \\
Central-nervous-system triggered & 31 & 0.56 \\
Tapetoretinal degeneration & 29 & 0.52 \\
Malformations of the eye & 14 & 0.25 \\
Corneal opacification & 13 & 0.25 \\
Cataract & 11 & 0.20 \\
Vascular occlusions of the eye & 10 & 0.18 \\
Retinal detachment & 7 & 0.13 \\
Chorioretinitis and choroideremia & 7 & 0.13 \\
Retinopathy of prematurity & 7 & 0.13 \\
Iritis and uveitis & 5 & 0.09 \\
Encephalomyelitis and neuritis nervi optici & 4 & 0.07 \\
Other & 5 & 0.09 \\
? & 4 & 0.07 \\
\hline Total & 647 & \\
\hline
\end{tabular}

tion is the cause of blindness for nearly one fifth of cases $(1.92 / 100,000)$. Thus, these two diseases are responsible for more than half of all cases. Myopia, glaucoma, tapetoretinal degeneration, optic atrophy and central-nervous-systemtriggered blindness number similarly in this age group (57\%). All other blinding diseases are less common.

In old persons (age $>74$ years), the leading cause of blindness is macular degeneration affecting nearly half of all newly blind (incidence 54.3/100,000 of the population). One fifth of all cases lost vision due to glaucoma (incidence 22.8/100,000). Every tenth blind individual in this age group lost vision due to diabetic retinopathy. All 
Table 5. Causes of blindness according to age group

\begin{tabular}{|c|c|c|c|c|c|c|c|c|}
\hline \multirow[t]{2}{*}{ Cause of blindness } & \multicolumn{2}{|c|}{ Age $<15$ years } & \multicolumn{2}{|c|}{ Age $15-44$ years } & \multicolumn{2}{|c|}{$15-74$ years } & \multicolumn{2}{|c|}{ Age $>74$ years } \\
\hline & cases & incidence & cases & incidence & cases & incidence & cases & incidence \\
\hline Cataract & & & 2 & 0.08 & & & 8 & 2.42 \\
\hline Central-nervous-system triggered & 9 & 0.94 & 7 & 0.28 & 10 & 0.55 & 5 & 1.52 \\
\hline Choroideremia chorioretinitis & & & 2 & 0.08 & 3 & 0.16 & 2 & 0.61 \\
\hline Corneal opacification & & & & & 4 & 0.22 & 8 & 2.42 \\
\hline Diabetic retinopathy & & & 6 & 0.24 & 68 & 3.74 & 38 & 11.53 \\
\hline Glaucoma & & & & & 12 & 0.66 & 75 & 22.75 \\
\hline Glaucoma, congenital & & & 2 & 0.08 & & & & \\
\hline Iritis/uveitis & & & & & 3 & 0.16 & 2 & 0.61 \\
\hline Macular degeneration & & & & & 35 & 1.92 & 179 & 54.29 \\
\hline Macular degeneration, juvenile & & & 3 & 0.12 & & & & \\
\hline Malformations & 2 & 0.21 & 7 & 0.28 & 4 & 0.22 & & \\
\hline Myopia & & & 3 & 0.12 & 13 & 0.71 & 26 & 7.88 \\
\hline Ocular vessel occlusion & & & & & 2 & 0.11 & 8 & 2.42 \\
\hline Optic atrophy & 4 & 0.42 & 6 & 0.24 & 10 & 0.55 & 18 & 5.46 \\
\hline Optic neuritis/multiple sclerosis & & & 2 & 0.08 & 2 & 0.11 & & \\
\hline Retinal detachment & & & & & 3 & 0.16 & 3 & 0.91 \\
\hline Retinopathy of prematurity & 5 & 0.52 & 2 & 0.08 & & & & \\
\hline Tapetoretinal degeneration & & & 17 & 0.69 & 11 & 0.60 & & \\
\hline Others & 2 & 0.21 & 4 & 0.16 & 3 & 0.16 & 3 & 0.91 \\
\hline Unknown & & & & & 1 & 0.05 & 3 & 0.91 \\
\hline Total & 22 & & 23 & & 184 & & 378 & \\
\hline
\end{tabular}

Incidence calculated per 100,000.

other causes of blindness account for roughly one fifth of cases. In this age group no cause of blindness could be determined for 3 cases.

\section{Age at Onset of Blindness in Regard to Cause of Blindness}

The distribution of age of onset of glaucomatous blindness (excluding congenital glaucoma) is shown in table 6 . Virtually all blind persons with glaucoma lost sight after the age of 65 years. The majority (approx. $75 \%$ ) turned blind in the age range of 75-89 years.

Macular degeneration (excluding juvenile forms) causes blindness predominantly in late life. More than $70 \%$ of newly blind persons due to these diseases are 80 years of age and older (table 6). Only few cases occur before the age of 65 years.

Subjects that lost sight due to diabetic retinopathy do so at a younger age. Most newly diabetic blind people are 55-79 years of age. In our data 2 cases turned blind before the age of 30 years. Subjects older than 80 years present a minority in the diabetic blind. All new diabetic blind persons above this age $(>80)$ in this study were female.

\section{Residual Visual Acuity with Regard to Main Cause of} Blindness

The residual visual acuity for the three main causes of blindness is shown in table 7. In the blind group with glaucoma more cases of amaurosis and visual acuity $<0.01$ are present, but also more persons with visual acuity better than $0.05(1 / 20)$. In the macular degeneration group more than two thirds of cases had a residual visual acuity of $0.01-0.02$.

\section{Discussion}

In Germany blind citizens are entitled to a monthly monetary support (independently of other revenues). As had been shown $[8,9]$, monetary support for blind persons (as this is the case for the UK and Germany) is related to accurate and complete registry data. In contrast, membership in associations for the blind does not provide complete data [10]: only one third of the blind subjects registered with the social services are also members of the German Association for the Blind. Especially those blind 
Table 6. Blindness incidence according to major causes, age and sex

\begin{tabular}{|c|c|c|c|c|c|c|c|c|c|c|c|c|}
\hline \multirow{3}{*}{$\begin{array}{l}\text { Age } \\
\text { years }\end{array}$} & \multicolumn{4}{|c|}{ Macular degeneration } & \multicolumn{4}{|c|}{ Glaucoma } & \multicolumn{4}{|c|}{ Diabetic retinopathy } \\
\hline & \multicolumn{2}{|c|}{ cases } & \multicolumn{2}{|c|}{ incidence } & \multicolumn{2}{|c|}{ cases } & \multicolumn{2}{|c|}{ incidence } & \multicolumn{2}{|c|}{ cases } & \multicolumn{2}{|c|}{ incidence } \\
\hline & $\mathrm{m}$ & $\mathrm{f}$ & $\mathrm{m}$ & $\mathrm{f}$ & $\mathrm{m}$ & $f$ & $\mathrm{~m}$ & $\mathrm{f}$ & $\mathrm{m}$ & $\mathrm{f}$ & $\mathrm{m}$ & $\mathrm{f}$ \\
\hline$<65$ & 1 & 7 & 0.04 & 0.30 & 1 & 1 & 0.04 & 0.04 & 14 & 13 & 0.57 & 0.56 \\
\hline $65-69$ & 3 & 4 & 2.68 & 2.91 & 3 & 3 & 2.69 & 2.19 & 6 & 19 & 5.37 & 13.85 \\
\hline $70-74$ & 3 & 18 & 3.91 & 13.13 & 3 & 1 & 3.91 & 0.73 & 6 & 20 & 7.82 & 14.59 \\
\hline $75-79$ & 5 & 14 & 13.19 & 18.19 & 7 & 12 & 18.46 & 15.59 & 3 & 14 & 7.91 & 18.19 \\
\hline $80-84$ & 17 & 50 & 43.14 & 56.13 & 3 & 18 & 7.61 & 20.20 & & 8 & & 8.98 \\
\hline $85-89$ & 12 & 51 & 68.17 & 110.21 & 6 & 18 & 34.08 & 38.90 & & 7 & & 15.12 \\
\hline $90+$ & 6 & 23 & 113.91 & 134.16 & 4 & 6 & 75.94 & 34.00 & & 2 & & 11.67 \\
\hline Total & 47 & 167 & & & 27 & 59 & & & 29 & 83 & & \\
\hline
\end{tabular}

$\mathrm{m}=$ Male; $\mathrm{f}=$ female

persons who lost sight in old age or suffer from multiple morbidity are not adequately represented. Self-selected populations in epidemiological field studies may have a similar bias. Thus, analysing data from the social services gives a complete picture of blindness in Germany. However, the depth of information is restricted. The social services must limit their data/information demand to facts needed for checking whether persons applying for blindness compensation fulfil the legal definition of blindness: visual acuity less than $1 / 50$ or other ocular conditions leading to similar decreased visual capacity.

ICD coding as recommended by Thylefors et al. [11] has not been performed. The coding of causes of blindness used clinical terminology to be comparable to recent studies on incidence (and prevalence) of blindness [8, 12-14].

Statistics on the incidence of legal blindness in industrialised countries are sparse. More recent statistics are from the UK $[13,15,16]$. In the UK a system of social support for the blind has been introduced in 1948 (to some extent comparable to that of Germany). To achieve monetary benefits blind persons must obtain a certificate of blind registration from a consultant ophthalmologist. However, the incidence of legal blindness is dependent on the visual loss specified in the definition. With regard to World Health Organisation [17] criteria, the German definition of blindness would best match category 4 (vision $<1 / 50$ ), whereas the British definition would match category 3 (vision $<1 / 20$ ). Expectedly after indirect standardisation to the population of Avon the incidence of legal blindness is much lower in Württemberg-Hohenzollern than in Avon: 12.0/100,000 compared to $30.6 / 100,000$ [13] (population data provided by the Office for National

Blindness Incidence in Germany
Table 7. Residual visual acuity in regard to cause of blindness

\begin{tabular}{lccc}
\hline Visual acuity & $\begin{array}{l}\text { Macular } \\
\text { degeneration, \% } \%\end{array}$ & $\begin{array}{l}\text { Glaucoma } \\
\%\end{array}$ & $\begin{array}{l}\text { Diabetic } \\
\text { retinopathy, \% }\end{array}$ \\
\hline Amaurosis & 1.9 & 4.6 & 2.7 \\
$<0.01$ & 16.4 & 24.4 & 22.3 \\
$0.01-0.02$ & 68.2 & 39.5 & 48.2 \\
$0.021-0.05$ & 13.1 & 9.3 & 22.3 \\
$0.051-0.3$ & 0.5 & 18.6 & 4.5 \\
$>0.3$ & 0 & 2.3 & 0 \\
$?$ & 0 & 1.2 & 0 \\
\hline
\end{tabular}

Statistics [pers. commun.]. Similar to studies from the UK, the incidence of blindness in Germany is higher in females than in males $[13,16,18]$. Female sex and higher age have also been described as predictors for poor visual acuity in the Beaver Dam Eye Study [19].

The population is ageing rapidly in industrialised countries and thus blindness incidence and prevalence will increase further [20]. An increasing prevalence of blindness in Germany has been shown in a previous study [21].

Causes of blindness have been investigated starting from registries of the social services $[13,16,18]$. Due to already mentioned differences in blindness definition some causes of blindness have a higher incidence in Avon as compared to Germany (table 8). As the Avon study did not provide sex-specific incidence rates, these comparisons lack the respective standardisation. Given these restrictions, blindness registration due to macular degen- 
Table 8. Rates of registration of blind persons per 100,000 population for common disorders: comparison of Avon 1985-1986 (AV) [13] with Württemberg-Hohenzollern 1994 (WH)

\begin{tabular}{|c|c|c|c|c|c|c|c|c|}
\hline & \multicolumn{2}{|c|}{ Age $50-59$ years } & \multicolumn{2}{|c|}{ Age $60-69$ years } & \multicolumn{2}{|c|}{ Age $>70$ years } & \multicolumn{2}{|c|}{ All ages } \\
\hline & AV & WH & $\mathrm{AV}$ & WH & $\mathrm{AV}$ & WH & $\mathrm{AV}$ & WH \\
\hline Macular degeneration & - & 0.43 & 4.9 & 1.66 & 128.0 & 25.11 & 15.0 & 3.92 \\
\hline Diabetic retinopathy & 0.5 & 1.58 & 9.5 & 4.00 & 5.2 & 7.70 & 1.9 & 2.01 \\
\hline Glaucoma & - & 0.14 & 2.8 & 1.06 & 37.0 & 9.84 & 4.7 & 1.60 \\
\hline High myopia & 0.7 & 0.72 & 0.8 & 0.76 & 10.1 & 3.66 & 1.3 & 0.77 \\
\hline Cataract & - & - & 0.3 & - & 5.0 & 1.14 & 0.6 & 0.20 \\
\hline
\end{tabular}

eration is nearly 4 times more common in the UK than in Germany.

In general, the relative distribution of causes in different other regions is similar to the study area (Bavaria, Germany [22]; Avon, UK [13]; Bradford, UK [15]; Scotland, UK [16]): macular degeneration is the most frequent cause of blindness affecting at least $30 \%$ of newly blind subjects. Glaucoma, high myopia and optic atrophy have similar relative frequencies (10-15\%). However, these comparisons have not been standardised (e.g. with respect to sex or age).

\section{Conclusions}

Blindness incidence and prevalence will increase further. The most frequent cause of blindness is macular degeneration, though, put together, diabetic retinopathy and glaucoma have a similar incidence. For the latter, blindness prevention is conceivable. Thus, the results of this study point to the initiation of co-ordinated activities to prevent blindness for diabetic retinopathy and glaucoma.

\section{References}

1 Statistisches Bundesamt: Blindengeld in Deutschland. Dtsch Ärztebl 1995;92:B795.

2 Gramberg-Danielsen B (ed): Medizinische Grundlage der augenärztlichen Begutachtung. Stuttgart, Enke Verlag, 1996 (Bücherei des Augenarztes; Bd. 126).

3 LARS Leistungsstarkes Archivierungs- und Recherchesystem, Version 3.4. Frankfurt am Main, Midas Micro Datensysteme $\mathrm{GmbH}$, 1989.

4 SAS Institute Inc: SAS Language Guide: Reference, Version 6, ed 1. Cary, SAS Institute, 1990.

5 Breslow NE, Day NE: Statistical Methods in Cancer Research - The Analysis of Case-Control Studies. Lyon, IARC: 1980.

6 Hartung J, Elpelt B, Klösener KH: Statistik: Lehr- und Handbuch der angewandten Statistik. München, Oldenbourg, 1985.

7 Statistisches Bundesamt: Statistisches Jahrbuch 1996 für die Bundesrepublik Deutschland. Stuttgart, Metzler-Poeschel, 1996.

8 Gibson JM, Lavery JR, Rosenthal AR: Blindness and partial sight in an elderly population. Br J Ophthalmol 1986;70:700-705.
9 Trautner C, Icks A, Haastert B, Plum F, Berger M, Giani G: Diabetes as a predictor of mortality in a cohort of blind subjects. Int $\mathrm{J}$ Epidemiol 1996;25:1038-1043.

10 Herzog HW, Kügle M: Untersuchung zu technischen Hilfmitteln für Blinde. Infratest Gesundheitsforschung. Endbericht 784896. München, HWJH/KU/wd, 1982.

11 Thylefors B, Negrel AD, Pararajasegaram R, Dadzie KY: Global data on blindness. Bull WHO 1995;73:115-121.

12 Anand JK, Leitch JA, Roberts JT: Blindness and partial sight: Aetiological factors and data collection systems. Public Health 1990;104: 257-260.

13 Grey RHB, Bruns-Cox CJ, Hughes A: Blind and partial sight registration in Avon. $\mathrm{Br} \mathrm{J}$ Ophthalmol 1989;73:88-94.

14 Nicolosi A, Marighi PE, Rizzardi P, Osella A, Miglior S: Prevalence and causes of visual impairment in Italy. Int $\mathrm{J}$ Epidemiol 1994;23: 359-364.

15 Yap M, Wetherill J: Causes of blindness and partial sight in the Bradford Metropolitan District from 1980 to 1985 . Ophthalmic Physiol Opt 1989;9:289-292.
16 Ghafour IM, Allen D, Foulds WS: Common causes of blindness and visual handicap in the west of Scotland. Br J Ophthalmol 1983;67: 209-213.

17 WHO: International Classification of Diseases and Related Health Problems, rev 10. Geneva, WHO, 1992, vol 1.

18 Sorsby A: The incidence and causes of blindness in England and Wales 1963-1968. Department of Health and Social Security, Report on Public Health and Medical Subjects No 128. London, HMSO, 1972.

19 Klein R, Klein BEK, Linton KLP. De Mets DL: The Beaver Dam Eye Study: Visual acuity. Ophthalmology 1991;98:1310-1315.

20 Pizzarello LD: The dimension of the eye disease among the elderly. Ophthalmology 1987; 94:1191-1195.

21 Krumpaszky HG, Klauss V: Epidemiology of blindness and eye disease. Ophthalmologica 1996;210:1-84.

22 Krumpaszky HG, Klauss V: Erblindungsursachen in Bayern. Klin Monatsbl Augenheilkd 1992;200:142-146. 